Performing the High School Prom in the UK: Locating Authenticity through Practice

Dr Julie Tinson

Senior Lecturer

Marketing Division

Stirling Management School

University of Stirling

Stirling

FK9 4LA

Telephone: 01786467389

Fax: 01786464745

Email: j.s.tinson@stir.ac.uk

\&

Dr Peter Nuttall

Lecturer

School of Management

University of Bath

Bath BA2 7AY

UK

Telephone: 01225386742

Fax: 01225386473

Email: p.nuttall@bath.ac.uk 


\title{
Performing the High School Prom in the UK: Locating Authenticity through Practice
}

\begin{abstract}
The purpose of this study was threefold: to develop an understanding of the appropriation of the US High School Prom in the UK and more importantly to generate an insight into the producers and consumers of such an event; to establish if the performance of the prom is hyper-real or if there is an awareness of the authentic or inauthentic elements of this ritual and finally to ascertain local interpretation of authenticity and glocal practice. The method used here was a qualitative approach employing 24 in-depth interviews with young adults (18-20 years) who had attended a prom in the UK in the last three years. The findings illustrated that the role and the social network of the individual was key to engagement with the High School Prom and also indicated a possible symbiosis of the strands of theory associated with authenticity. Diverse localised meanings of the prom performance were also identified. As the school prom is a growth market in the UK businesses should be aware of adolescents' desire for ownership of this event and should tailor their marketing accordingly.
\end{abstract}

\section{Key Words}

Adolescence, Authenticity, Qualitative Research, Rituals, Organisation and Practice

\section{Biographies}

Dr Julie Tinson is a Senior Lecturer in Marketing at the University of Stirling where she principally teaches Consumer Behaviour and Marketing Communications. Her research interests include family decision making and consumer socialisation. She has published widely on consumer behaviour in relation to families and children and has recently written a book on how to research with children and adolescents. Consultancy includes work for Associa (NFU), Barclays Bank, Tpoll and Channel 4.

Dr Peter Nuttall is a Lecturer in Marketing in the School of Management at the University of Bath. He teaches in the areas of international marketing and marketing communications and is also a visiting associate professor at Malta University. His publications have been focused primarily in the field of adolescent and young consumer behaviour. More specifically his research has explored the consumption and use of popular music as a means of expressing identity and the impact of family structure and peer group affiliation on this consumption behaviour. Consultancy work has centred on consumer market research in the charity and not-for-profit sector. 


\section{Introduction}

Ten years ago High School Proms were an exclusive part of American life but in the past decade it has become the ultimate coming of age celebration for adolescents living in the UK (Duffy, 2007). It would seem, albeit superficially, that in the UK youth culture has embraced this global ritual and have adopted it as if it were their own. Yet simply (re) producing a US High School Prom in the UK does not ensure consumption as forms of marketable popular culture do not simply coerce adolescents to behave in a particular manner. The authentic (re) creation of an event such as the High School Prom requires the integration of 'production' and 'consumption' (Munoz et al., 2006) and its evaluation would undoubtedly involve considering the inter-dependence of these processes. Adolescents have to identify with the production in some way to accept the practice because as well as the frivolous in popular culture there are also 'elements of recognition and identification, something approaching a re-creation of recognisable experiences and attitudes to which people are responding' (Hall, 2006: 482).

These recognisable experiences do not necessarily imply the homogeneity of the youth market; it may be that aspects of experiences (e.g. seen in film) can be differentially appropriated or authenticated in the performances practised by adolescents. The degree to which the prom performed in the UK has re-created or simply re-enacted the US High School Prom (if at all) and which authentic elements, if any, have been central to its appropriation has been under-researched. The varying degrees of (re) appropriation and those central to organising, acknowledging or even agreeing the authentic aspects of a prom also needs further exploration. This will contribute to our understanding of the extent to which youth culture and associated authentic practices are homogenous. 
Authenticity, however, is not a simple concept and has been researched in a variety of contexts. For example, consumer researchers have explored the authenticity of food and drink offerings (Brown and Patterson, 2000; Sukalakamala \& Boyce, 2007); museums, artefacts and art (Grayson \& Shulman, 2000; Grayson and Martinec, 2004); authentic environments (Lego et al, 2002; Munoz et al, 2006); the ability of consumers to authenticate advertising claims (Beverland et al, 2008) and music authenticity with specific reference to Hip Hop (Clay, 2003).

Encapsulating the findings from previous studies, there would appear to be two opposing views on authenticity; the first being supportive of Baudrillard (1983) who suggests that as consumers we experience a pre-prepared or 'hyper-reality'. The inability of consumers to distinguish between fantasy and reality suggests that simulation can be substituted for genuine experience. Rose and Wood (2005) are proponents of this theory although they posit consumers can be reflexive when considering their experiences and suggest 'hyperauthenticity' is a more appropriate term than 'hyper-reality'. Conversely, Grayson and Shulman (2000) suggest that consumers can differentiate between the authentic and the inauthentic with Grayson and Martinec (2004) providing attributes (indexes and icons) that influence the process of authenticity. In particular, these authors call for further research in markets where iconicity with the 'old' is not important and question as a result which cues for authenticity would come to the fore. In the context of the UK High School Prom indexical cues (e.g. a dress imported from the States) may become exclusively predominant or perhaps other iconic cues (e.g. an authentic reproduction of a dress from a US prom) would gain more influence. 


\section{Notions of Authenticity}

Adolescents use the media for entertainment, identity formation, sensation-seeking, coping and youth culture identification (Ferle et al, 2000) and their ability to observe and learn from the media facilitates the socialisation process (O’Guinn and Shrum, 1997). Undoubtedly they will also use the media as a way of observing global teenage practice. Arnett (1995) has supported the idea that adolescents use media to help understand and define their environment, making active choices about the media they use according to their personalities, socialisation needs and personal identification needs. Teenage culture, however, has been described as a 'a contradictory mixture of the authentic and the manufactured: it is an area of self expression for the young and a lush grazing pasture for commercial providers' (Hall and Whannel, 2006: 47). This suggests that agency associated with adolescent active choice regarding the media is in some way controlled, restrained or manipulated by the producers of teenage culture. Hall (2006) reflects that the study of popular culture has a tendency to fluctuate between containment and resistance - with those resisting still linked in some way to a dominant social culture. As a consequence, it would appear that even though there may be variations in the practices of youth culture, these occur within pre-existing or managed boundaries.

\section{Agency and Adolescent Consumption Practices}

Hollensen (2007) supports the assertion that youth is homogeneous across national markets and that youth cultures are more international than national. He suggests that cross border segmentation opportunities are readily available and that regional or even global segments offer the chance to employ standardized approaches. However, Kjeldgaard \& Askegaard (2006: 246) have posited that the "oft- noted homogeneity of global youth consumption practices overlooks deeper structural differences and diverse localized meanings”. That is, 
although Gottdiener (1997) and Ritzer (1999) suggest commercial producers control consumer's desires, consumers and producers have been said to co-construct or negotiate meanings - adapting or localising styles (Arnould and Thompson, 2005; Kjeldgaard \& Askegaard, 2006). Firat and Venkatesh (1995) proposed that future research should explore the degree to which consumers, rather than producers, marketers or 'the market' manage their own reality or authentic practices. It may be that the youth market is more 'savvy' regarding popular culture and as a consequence more pre-disposed to being creative, subversive or idiosyncratic in relation to controlling their own reality (See Nancarrow et al, 2008; Kozinets et al., 2004).

\section{Authenticity and the High School Prom}

Before exploring the way/s in which the US High School Prom is appropriated in the UK and possibly more importantly the degrees of influence relative to its (re) creation it would be pertinent to explore how UK school pupils are able to recognise the ritual practices associated with the US prom. The active choice of media as outlined above and the proliferation of US network programming has enabled youth access to cultural practices on a global scale (perhaps, for some authors, reinforcing the notion that the youth are a global segment). US teen based dramas including 'The Hills' and the 'OC' are illustrative of the type of exposure youth in the UK will have had to the 'hyper-real' version of the prom; with MTV's 'Once Upon a Prom’ perhaps less simulated to reflect a particular story line or director's view.

In recent years, social commentators have also observed the phenomenon of 'High School Musical' which shocked even hardened movie executives. High School Musical features, as part of the narrative, the US Prom with Zac Efron and Vanessa Hudgens playing high-school sweethearts from rival social groups. Although the budget was modest, the 2006 original 
became the most outstanding break-out success in the history of the Disney Channel, and has been seen by 250 million viewers worldwide. Some 191 million have seen High School Musical 2 (Singh, 2008). Given the viewing figures associated with these films alone (and with Disney’s current proposal to re-make High School Musical for an Asian market using Chinese actors) the ritual artefacts, script, performance and audience for this event (See Rook 1985) are widely depicted in popular culture (albeit in a somewhat simulated fashion). It is of course also possible that with extended travel opportunities, family diasporas and social networking that alternative approaches to the US High School Prom are known and influence decisions made about the creation, re-enactment or re-creation of this event in the UK.

\section{Authenticity and the Organising Committee}

Arguably one of the most significant developmental aspects for an adolescent in the UK is leaving high school or sixth form to continue with further education and/or to find employment (See for example: Hektner, 1995). In order to recognise this milestone in the UK, traditionally there would have been a disco in the school gym where pupils would be expected to perhaps invest in a new pair of jeans and some hair products (Pyke and Bloomfield, 2004). As identified above, the High School Prom has now replaced this timehonoured end of school celebration in many UK schools (quite possibly as a consequence of exposure to popular culture) but how this ritual event is appropriated and more importantly by whom needs further exploration.

Best (2000) notes that for the US prom, teachers and pupils will assemble to discuss the most important decisions associated with this event and these include the: prom theme, location, menu, decorations, remembrance gifts, ticket prices and music. Of course not all students or pupils will be part of this assembly or 'organising committee'. The organising committee will 
then become not only consumers of the prom but also the producers of the event. The UK High School Prom organising committee will effectively manage its own reality and negotiate authenticity (Arthur, 2006) as each culture has to define what is genuine, real or trustworthy. Whilst appropriation of the prom can be described as a group borrowing or imitating the design or practices of another to call them their own (Shugart, 1997; Ostergaard et al, 1999) if not all consumers are members of the event production team (or at least affiliated to it in some way), the (re) creation of the prom in the UK will be appropriated by a specific social group.

Best (2000: 28) suggests that social control operates in the context of High School Prom. In relation to attendance she posits that 'the fear of having missed the prom is harnessed as a mechanism to gain students consent to this event and the material and ideological conditions it secures'. Employing social control, however, could also be applicable to those on the organising committee; those producing, agreeing and acknowledging how the prom should be performed or appropriated. The organising committee members will be drawn (selected or even self selected) from friendship or social groups of pupils across the cohort. Ennett and Bauman (1996) in their study of adolescent social networks identified three types of social groups: clique members, liaisons and isolates. Although 'clique membership was the modal social position pattern, liaisons and isolates were also well represented' (ibid: 194). That is, the degree to which those on the organising committee are representative of those attending the prom (and taking into account their inter-relationships with others in the year) is likely to shape the degree to which the performance is appropriated to the satisfaction of all those taking part. Nuttall (2010a) suggests that "there will be a number of different levels of engagement given the type of affiliation an individual has with the collective" and it is unlikely that all the individuals associated with the prom will behave towards it in a uniform 
fashion. However the engagement of those involved in organising the prom may be related to their social network as well as their individual agency and decisions made regarding the (re) creation of the prom will not be equitable across adolescent social groups. The role of the school as a socialisation agent relative to commercialism (See Buckingham, 2009) and consumption practices could also be explored in this context although this is outside the scope of this paper.

\section{This Study}

This study is designed to explore not only how the US High School Prom is appropriated in the UK but to develop a deeper understanding of the production and consumption of the prom and the relative influence of differing agentic ability and motivation amongst those involved. As a consequence, the following objectives have been set:

- To develop an understanding of the appropriation of the prom with specific reference to the organising committee and perceptions of the differences (or distinction) between 'producers' and 'consumers'.

- To establish if the prom as performed in the UK is a hyper-real (simulated) event or whether there is an understanding amongst consumers of the authentic and the inauthentic

- To explore local interpretation of authenticity and glocal practice in relation to end-ofschool celebration/s

\section{Method}

Given the exploratory nature of this study and the potential complexity in studying this phenomenon, a two stage in-depth interview approach appeared to be the most appropriate 
method to address the issues raised. The research involved a total of 24 in-depth interviews with the first twelve interviews designed to be more general and to capture the overall perceptions of young adults (18-20 years of age) regarding their High School Prom. These respondents had already attended a High School Prom (and the sample included those from England, Ireland and Scotland) and a semi-structured interview guide was developed for the data collection phase. Questions ranged from an initially broad approach with questions such as 'tell me about your school prom' with later questions addressing the specific aspects of the prom as a ritual such as 'how do you think your prom differed from that of a US prom' and 'how important was the prom for your year group' to 'why do you think some people did not attend the prom' and 'did some people feel obliged to go the prom'.

Having analyzed the first set of data and as a consequence of identifying the recurring themes the second set of twelve interviews with a new sample was designed to further develop specific aspects of the prom that had been explored somewhat cursorily in the first stage of research. For example, whilst the first set of interviews suggested that respondents on the organizing committee had a different 'prom experience' to those who simply attended the prom the second set of interviews explored the notions of production and consumption to a greater extent (providing examples from the initial interviews for comparative purposes) identifying perceptions of the distinction between those who produced and consumed the prom with those who simply consumed. This is more akin to a phenomenological research strategy that employs an inductive process that acknowledges a 'mutual simultaneous shaping of factors' and an emergent design that encourages the identification of categories, concepts and issues as they appear during the research (Hussey and Hussey, 1997: 48). 
The sampling approach for the stages of in-depth interviewing also varied (See Tables 1 and Table 2). Whilst the sampling approach employed for the initial interviews could be considered as a convenience sample, for the second set of interviews a purposive sample was adopted. The initial twelve interviews attracted a high proportion of female respondents and there was no incentive given to recruit or reward those taking part. The sample was principally recruited using the social network of the authors. There was, however, a mixture of students and full-time employed respondents taking part. To recruit participants for the second set of interviews the following promotion was sent out via email to management students in their first year of university in Scotland: 'High School Prom Research: $£ 10$ to tell me 10 things about your prom'. The student sample was recruited within less than a few hours and six of the respondents were male. The students were screened and selected on the basis of gender, length of time since their prom (within the last 24 months) and their role or otherwise on the organizing committee. The sample was also more domestic (Scottish).

The apparent enthusiasm of the respondents may have reflected the incentive but could equally be attributed to the interest the students had in their recently attended prom. Although some respondents did come to the interview with ' 10 things' about their prom written down, others simply turned up with specific stories to relate and/or were happy to be guided by the semi-structured questions asked by the interviewer. Each interview lasted between 30-40 minutes with one lasting only 25 minutes and a couple lasting over 50 minutes. Both stages of interview data collection were sufficient to ensure saturation (Guest et al 2006). 
Table 1

Sample of Interview Respondents (First Stage)

\begin{tabular}{|c|c|c|c|c|c|}
\hline Pseudonym & Gender & Age & Location of prom & $\begin{array}{c}\text { Time } \\
\text { elapsed } \\
\text { since prom } \\
\text { attendance }\end{array}$ & $\begin{array}{c}\text { Member } \\
\text { of } \\
\text { organizing } \\
\text { committee }\end{array}$ \\
\hline Lorna & $\mathrm{F}$ & 18 & Central Scotland & 1 year & $\mathrm{N}$ \\
\hline Karen & $\mathrm{F}$ & 19 & South East England & 2 years & $\mathrm{N}$ \\
\hline Keri & $\mathrm{F}$ & 20 & Northern Ireland & 2 years & $\mathrm{N}$ \\
\hline Hannah & $\mathrm{F}$ & 19 & North East England & 1 year & $\mathrm{N}$ \\
\hline Sarah & $\mathrm{F}$ & 20 & Central Scotland & 2 years & $\mathrm{Y}$ \\
\hline Ruth & $\mathrm{F}$ & 18 & Central Scotland & 1 year & $\mathrm{Y}$ \\
\hline Francesca & $\mathrm{F}$ & 20 & Central Scotland & 3 years & $\mathrm{N}$ \\
\hline Anna & $\mathrm{F}$ & 20 & Central Scotland & 3 years & $\mathrm{Y}$ \\
\hline Amy & $\mathrm{F}$ & 19 & South West England & 1 year & $\mathrm{N}$ \\
\hline Jamie & $\mathrm{M}$ & 19 & Highlands & 2 years & $\mathrm{N}$ \\
\hline Alex & $\mathrm{M}$ & 20 & Scottish Borders & 3 years & $\mathrm{N}$ \\
\hline David & $\mathrm{M}$ & 18 & Northern Ireland & 1 year & $\mathrm{N}$ \\
\hline
\end{tabular}

Table 2

Sample of Interview Respondents (Second Stage)

\begin{tabular}{|l|l|l|c|c|c|}
\hline Pseudonym & Gender & Age & Location of prom & $\begin{array}{c}\text { Time } \\
\text { elapsed } \\
\text { since prom } \\
\text { attendance }\end{array}$ & $\begin{array}{c}\text { Member } \\
\text { of } \\
\text { organizing } \\
\text { committee }\end{array}$ \\
\hline Scot & M & 19 & Edinburgh & 1 year & N \\
\hline Josh & M & 19 & Derby & 1 year & Y \\
\hline Jack & M & 18 & Glasgow & 4 months & N \\
\hline Graeme & M & 18 & Scottish Borders & 10 months & N \\
\hline Alastair & M & 18 & Highlands & 4 months & Y \\
\hline Elliot & M & 19 & Central Scotland & 4 months & N \\
\hline Kate & F & 18 & Central Scotland & 4 months & Y \\
\hline Eve & F & 19 & Fife & 1 year & N \\
\hline Elle & F & 20 & Central Scotland & 2 years & N \\
\hline Lucy & F & 18 & Fife & 4 months & Y \\
\hline Jessica & F & 19 & Glasgow & 4 months & Y \\
\hline Christie & F & 19 & Central Scotland & 1 year & Y \\
\hline
\end{tabular}

This two stage approach to interviewing was considered to be extremely useful in providing an overall holistic and insightful set of data that could not be achieved by simply employing 
one stage of research. In particular, given the six month gap between the first stage and the second stage of interviewing, additional reading and theoretical underpinning was possible allowing a fuller exploration of the prom experience as perceived by the attendees.

For the analysis of both sets of interviews an interpretive analytic stance was adopted that drew on the transcriptions. The analysis of the first set of data explored themes in the responses of adolescents employed analytic induction (Bryman and Burgess, 1994) and the constant comparative method described by Glaser and Strauss (1967). Each interview was examined to gain a holistic understanding of the respondent making notes of themes as they transpired (See Thompson and Hirschman, 1995). All the themes were reviewed through iterations of comparison and re-reading. The interpretations developed were as a consequence of the relationship between emerging insights and prior assumptions (Spiggle, 1994) and the second stage of interviewing provided an opportunity to explore emerging issues and to further clarify aspects regarding prom consumption where insufficient detail was considered to have been gathered in the first set of interviews.

\section{Findings}

The following analysis firstly investigates the role and perceptions of the organizing committee in appropriating the US High School Prom in the UK. This precedes locating authenticity through practice which will then be examined; with an exploration of the localization and interpretation of authenticity to conclude.

\section{Appropriation and the Organizing Committee}

A number of the respondents in the sample were members of an organizing committee and even though not all interviewees were officially affiliated with this group, some were 
represented on the committee by a close friend/s. Membership of the committee and (self) s/election of those taking a role in appropriating the High School Prom varied although for the majority of schools in the sample, there was some procedure for appointing members to the prom organizing committee. Only one of the respondents revealed that there was no organizing committee at her school and that a teacher was (self) appointed to make the arrangements for that particular prom and only one respondent said there was no school involvement at all. Generally those on the organizing committee would either automatically have membership as a consequence of having another role e.g. head girl or deputy head girl or people would opt for different committees in their final year at school:

People put things up on a wall [in the school] saying "do you want to be on the prom committee, year book committee?" - all the different committees - and then people put their names on which sheet they wanted and then all the prefects got to pick because the teachers had picked prefects - so the people who were prefects got to pick [who was on the prom committee].

Ruth

In this scenario those already on the prom committee could choose members from their own social cliques and further build social capital in this way (Bourdieu, 1984). Bourdieu suggests it is possible for some 'practices' to offer greater social rewards than others, for example, heightened personal or social prestige by virtue of 'access to privileged social networks' (Warde, 2005). There was clearly a perception that some committee members were more equal than others:

I think there were people from each [social] group on the committee but our group is probably more dominant than the other groups so we did have more of a say...we're all quite opinionated as well so we probably made the [final] decision.

Christie 
Interestingly there was also some suggestion that prom committees attracted a particular type of person - perhaps those specifically seeking social capital:

Amy she decided she was in charge of everything - so I quit the committee. We said thank you to her for organizing it [the prom]. Like she even picked out the flowers she got. I've never met such a control freak.

Elle

As well as building social capital there was general agreement that pupils who (self) s/elected to be on the prom committee would benefit in the long-term from this role:

It was quite a prestigious thing to get chair of that [prom] committee because obviously it looks quite good on the CV

Graeme

It seemed, however, that only producers had an understanding of the responsibility associated with such an appointment as 'anything that went wrong the committee were to blame'. There were also some committee members who appeared to enjoy the kudos of the role whilst others appreciated that there was a job to be done:

I organised most of it because everyone else was too lazy. It was exciting at the timebut looking back on it being on the prom committee ruined it a bit because you knew the effort that had gone on behind the scenes

Sarah

With specific reference to the difference between the producers and the consumers the perception appeared to be one of 'them and us'. Whilst it was acknowledged that some choice was available (in relation to the venue etc.) these options seemed to be pre-determined by what the organizing committee had already decided:

We weren't given a choice. They sort of told us what they did. They went to view different venues and then came back again and gave us a choice then - obviously we got told the cost.

Kate 
Warde (2005) discusses practice in the context of social groups. That is, practice within a peer group may include identification, empowerment or social inclusion (or exclusion). To that end, the prom committee members could be considered as 'insiders' with their friends considered as 'regulars' as they had access to the committee practice. Those with no membership and no affiliation (although with some pre-determined 'choice') could be considered as 'tourists' (See Gronnow, 2004; Unruh, 1979). It would appear that in many of the experiences communicated in this study that there was an under-current of discontent, particularly amongst the 'tourists', with the way in which the producers or 'insiders' created the prom using their own preferences as a guide:

None of our ideas were taken into account. I think the organizing committee had what they wanted and it didn't matter what anyone else wanted, so it was their way or no way if that. I must admit there was a lot of grumbling leading up to the prom.

Eve

Although the need for the committee to be organised was acknowledged, in some cases this led to feelings of isolation:

We talked about it [the prom] at the start of the [academic] year and then it was kind of booked. I can understand why you would want to arrange everything to make sure everything is running smoothly but people kind of felt a little bit left out of what was happening

Jack

Where these issues of separation were unresolved, 'alternative' prom committees as a proxy had been considered, but generally the outcome for isolates (See Ennett and Bauman, 1996) was withdrawal. With regard to the practice of the prom, these isolates could also be described as ‘strangers' (Gronnow, 2004): for example 'there were one or two who didn't go to the prom because they didn't have their opinions taken on board'. 
In sum, the appropriation of the prom was principally decided upon by the producers or 'insiders' (the organizing committee) and was not always agreed on by those simply attending the prom. The perception was that the producers, who would also become consumers, used their own experiences and preferences to decide how best to appropriate the prom and were able to build social capital in the process. The perceived differences between the producer and the consumer groups suggested that those who were simply consuming the prom (particularly the 'tourists') had limited input in terms of venue and prom theme. Those consumers who were not on the organizing committee but were still affiliated in some way through their social network to committee members appeared somewhat to have a 'voice' in terms of production. The producers were aware of their (privileged) role but emphasized the responsibility associated with such a task (which was largely ignored by those only attending the prom).

The degree to which the prom was simulated will now be explored and the authentic practice relative to the individual contribution of consumers will also be investigated.

\section{Locating Authenticity in the Performance of the Prom}

In order to evaluate the authenticity of the US prom as performed in the UK (and more specifically in Scotland) it has been noted that the integration and inter-dependence of 'production' and 'consumption' ought to be considered (Munoz et al., 2006). However, it is also important to establish what the producers (e.g. the organising committee members) and the consumers (who ultimately include the producers in this instance) believe is 'real' in the context of this ritual event. This section will explore the signified reality of the prom as perceived by the consumers and experiential authenticity as well as legitimacy, iconic value, hyperauthenticity and authoritative performances. 
Baudrillard's (1983) notion of hypereality contends that in the absence or implausibility of the real (e.g. a US prom in Scotland) the consumer will turn to a signified reality and substitute signs of the real for the real itself. This was perhaps most evident in the expectations of the prom articulated by respondents which, for many, failed to be realised by the event itself. Preparation and the investment individuals had made were largely guided and motivated by a commonly shared hypereality:

Well that's thing, it's a competition of who has the nicest dress and the most expensive dress and who has the nicest way of getting there and who has the nicest date and who has the nicest hair - that is the thing [of most importance] - nothing about the actual night - everyone is just comparing each other.

Hannah

Interestingly, consumption for the prom appeared to be prioritised in the individual planning stage (constructed ahead of the event) with the majority of the expense incurred buying artefacts that had congruence with this hypereality. Disappointment with the event and its experiential authenticity (Cohen, 1979) was a common theme in the interviews and appeared to have a negative impact upon the respondent's post-rationalisation of the event:

I was [thinking] "what kind of dress will I get - a short one, like the big long ones types" and I decided I'd quite like a long one. It was quite expensive and then when I was sitting there [at the prom] I was like "gawd, all this for what?" you know, I wish I hadn't even bothered, you know I wish I'd got a cheaper dress.

Kate

Several respondents had reflected on their experiential authenticity and sought to reconcile their pre-conceived ideas and expectations by repositioning the event and its status in their lives:

It was significant at the time but with all the things that happen in life it is probably the least significant. It was just a party.

Francesca 
For others however, it carried greater significance and longevity, sustained through the use of photos on social networks and links to other, possibly more authentic artefacts from school (e.g. the school year book):

I don't think anyone I know has ever taken their prom photos off Bebo - they just kind of stay there. Some people even now have their prom picture as their profile picture - that makes them look popular as well.

Anna

According to Grayson and Martinec (2004) the perceived legitimacy of the event is derived from the assimilation of 'cues' generated through the production of the event. Like the pursuance of a hyperreality, this reflects an externalised process, reliant upon observable intangible and tangible signified 'attributes' belonging to the event or associated with it through individual and social adoption. All of the respondents referred to aspects of this process as part of their intent on authenticating (or not) the event and making credible their own or their friendship group's participation in it. For example some attendees had stretch hummers which they thought 'definitely compared' to the prom as practised in the US whilst others reflected on the artefacts - specifically the dress:

I had one friend who her mum and dad had spent like three hundred and fifty quid on her prom dress, right and then about two weeks before our prom she started crying because it wasn't THE ONE. So her parents bought her a second one which - so altogether including the shoes and both dresses - it was like a thousand pounds.

Scot

The dress was also somewhat evident in the notion of priority given to the icons chosen to represent the authenticity of the event: for example 'a lot of girls splashed out $£ 200, £ 300$ pounds on a dress - big fancy things' and whilst 'some people just got theirs [prom dress] from Jane Norman - others had theirs shipped in from America.' 
Given the expense associated with more important icons e.g. the dress, strategic trade-offs were apparent:

People were just like [concerned] with their dress and how much everything cost. I was just like "do you know what, I can't afford to" and we all kind of agreed let's not get a limo and nobody actually did in our year, they just got the bus.

Eve

It appeared then that some consumers were more economically savvy in relation to their consumption behaviour (See Nancarrow et al., 2008) and, that further to this, an idiosyncratic adoption of certain cues and artefacts uncovered what seemed to be an ironic appreciation of their iconic value (Kozinets et al., 2004):

I got my partner a corsage but that was almost more of a private joke a kind of laugh that we'd arranged."

Scot

This was apparent for both males and females:

One girl went in a white suit. I have to admit it looked amazing - really good - but I remember that she was always your typical girly girl - but she had a white suit on and I always remember that being very different.

Alastair

Hyperauthenticity, as defined by Rose and Wood (2005) is a reflexive connection between the event and an individual's personal reality through an active discourse. This demands a level of personal investment which, in turn, reflects the degree to which the prom represents an opportunity to extract self-authenticating meaning and (social) identity. Varying levels of investment were evidenced by the performance of authenticating acts and authoritative performances (Arnould and Price, 2000), such as a hand-made prom dress or tailored suit, a special date and performing the Ceilidh:

For [ideas about designing] my dress and stuff a lot of it came from my big sister. My sister's five years older than me but I'm quite close to her and her group of 
friends and believe it or not I had ideas about having my dress made from my sister's prom.

Elle

Again this was true for both males and females:

I think everybody does look forward to it [the prom] because I mean we practised the [Scottish] country dancing for like weeks and weeks up to it so you've got it quite perfect.

Graeme

One respondent revealed an authenticity derived from her own interpretation of the meaning of the prom as a rite of passage:

It was important to me because it was the first time I had stayed away with my boyfriend and I didn't tell my Mum at the time - that was quite significant for me because I felt quite independent.

Sarah

The prom then is a significant event in the lives of adolescents in the UK and is valued as both a rite of passage and a coming of age event and whilst there are clear differences in the tangible facets and attributes attached to the US and UK proms, respondents acknowledged its relevance and significance as an event with comparable meaning. The authentic (re) appropriation of the event materialised on several levels and corresponded with both the hypereal and the more reflexive hyperauthentic notions of a prom.

As the social-cultural context, local content and friendship group influence are cornerstones in the authenticating process the extent to which individuals made investments to authenticate their own experience/s will now be examined.

\section{Glocalising the Prom}

Having explored the production of the prom and notions of experiential authenticity, legitimacy and authoritative performances it would also contribute to our understanding of 
this phenomenon to establish the different ways in which consumers localised their prom. That is, to consider how the respondents in this sample effectively managed their own reality and negotiated authenticity as proposed by Arthur (2006). The consumers were asked to identify how they were aware of the US High School Prom, how it compared with their own, what their own prom meant to them and if indeed there was resistance to practices associated with the US prom.

Consumers drew a number of interpretations about the event in America which were largely consistent and stereotypical. Popular culture featured as playing a significant role in facilitating an understanding of this ritual. Most interestingly were the contrasts that exemplified perceived cultural differences:

I think our prom is very different to a US High School Prom... in America they have a junior prom, a middle school prom. They are more accustomed to that tradition where as we are not. They go all out and they spend so much money and have the proms in such big grand hotels and they stay overnight afterwards.

Ruth

This reflects the exclusive nature and cultural privilege of the US prom and its unique role in American life. Respondents were able to recognise the ritual practice associated with the US prom and gathered this from a number of mediated versions:

American TV shows and films give an idea of what the prom is about - but ours wasn't extravagant. Maybe it would have been nicer to have it in the same style [as the US prom].

Amy

Respondents seemed more confident in drawing a connection to elements they identified as indicative of their own recognisable experiences (Hall, 2006) as opposed to specific cultural nuances and characteristics of the American prom. Many of the respondents sought to 
describe the prom as a ritual that reflected the value of graduating not only from school but also in life:

I think the people who don't attend regret it in later years - it's a good way to say goodbye to everyone. It's a rite of passage for most teenagers. It's like American Pie - it's a way of moving on - and starting a new way of life.

The significance of the prom was often expressed in a social context. For some the prom was an important signifier of their belonging at school:

There were a few people who didn't go more kind of quieter people...you knew who wouldn't come and you would kind of say "oh, it's your last dance, please come, we kind of want you to be there" because in sixth year obviously it's more kind of like togetherness feeling because you've lasted well six years.

Josh

For others it represented the opportunity to demonstrate the integrity of their friendship group:

It was like we all knew that that was the last time we would see lots of people but we didn't really care, we still kept to our own friendship groups because our year wasn't very close so we still danced with our own friendship groups.

Jessica

Notably there was a general level of resistance towards the perceived level of commerciality and extravagance attached to the US prom. Similarly, resistance to the prom from a cultural perspective was evident alongside examples of appropriation that clearly reflected a more local interpretation and performance of the prom:

Our prom isn't as commercial as theirs [the Americans] - there's no prom king and there's no prom queen or court or anything like that. I think the whole prom thing is a bit too americanised anyway, the whole partner thing.

Christie 
This again was true of both perceptions of males and females:

I think coming from the [Scottish] Borders people didn't want a US prom. People were very reluctant to call it a "prom", it was always "the dance", and we always have a Ceilidh. I mean like we had no thoughts of any kind to put in like prom king or queen or anything like that so it was quite distinctive, like Scottish and I think that probably kind of reflects on where we came from like the Borders are quite rural.

Graeme

In some cases however there was a desire to place some distance between the local culture and embrace the global:

[If I were to have changed my prom] I wouldn't say have so much Ceilidh, do you know what I mean because we're not really interested in that.

Christie

It would appear from the respondents in this sample that whilst Hollensen (2007) supports the assertion that youth is homogeneous across national markets and that youth cultures are more international than national this analysis builds on the work of Kjeldgaard and Askegaard (2006) who indicate that youth have diverse localised meanings for consumption practices. Although those interviewed for this study were able to draw on the media and popular culture for an understanding of this particular ritual, not all individuals engaged with the practice in the same way and indeed some resistance to embracing this global phenomenon was apparent.

\section{Discussion}

This paper contributes to our understanding of the High School Prom phenomenon in three different ways. Firstly the notion of consumption and production has been explored and the idea that adolescence is not merely a market for commercial providers or even an area of self expression for the young has been developed (Hall, 2006). It is evident that some of the teenagers in this sample have adopted the role of producers and have, as 'insiders' (Gronnow, 
2004), decided upon the aspects or elements that 'make' a prom. Whilst aspects of their prom can be attributed to observation of popular culture the organising committee select the most relevant elements for themselves. These insiders were considered as elite by others in their cohort not only because of their social position and as a consequence their relative power but because they were exclusionary and only those in their social group (the regulars) had some access to this privileged network. Committee membership was also recognised as building social capital even by those not affiliated with the organising committee. Interestingly central writers do not value young people as active agents in the formation of social capital (Holland et al, 2007). Putnam (2000) for example whilst emphasising the importance of parental social capital did not consider the young capable of being able to obtain or utilise social capital yet there is clear evidence here that during this liminal phase of transition adolescents appreciate the nuances such a position holds and more importantly how it may be of use in the future as a resource. Further work to expand on the practice of the organising committee (See Warde, 2005) with specific reference to group affiliation and separation (See Kandel, 1996) would generate insight into this adolescent social network. Additional work on adolescent agency (Tinson and Nuttall, 2010a), to explore the extent to which individual agency can be can be overwhelmed and duped by the 'producers’ (Kozinets et al, 2004), should also be considered.

Secondly this paper illuminated the possible symbiosis of the strands of theory associated with authenticity. Whilst previous authors (Baudrillard, 1983; Rose and Wood, 2005) have suggested that authenticity is either simulated (hyper-real or hyper-authentic) or that authenticity can be recognised using icons or indexes (See Grayson and Martinec, 2004) the findings here suggest that whilst the preparation and investment individuals made for the prom were largely motivated by a commonly shared hyperreality, icons or cues were also central to how 'real' or genuine the consumers perceived the prom to be. Where cues were 
absent e.g. the lack of an organising committee or insufficient detail regarding the ritual script (See Rook, 1985) disappointment was expressed in the experiential authenticity (Cohen, 1979). Although there was some evidence of reflexivity particularly in the ability to recognise mediated versions of this ritual event, supporting Rose and Wood's (2005) notion of hyperauthenticity, the artefacts or cues were fundamental to a genuine (re) creation of the prom.

Interestingly for some consumers an authentic or genuine prom was one which least represented their perception of the US version. Perhaps for those with a greater sense of felt Scottish identity (See Nancarrow et al., 2007), although this would require further research, there appeared to be some resistance to embracing the global. If authenticity is a function of separation, in some cases, an authentic prom would be one which was least like that of a US prom. This appeared to be the exception rather than the norm but the distinctive nature of the Scottish Border's prom or dance illustrated the paradox of authenticity as the greater the degree of separation the more 'real' this prom or dance became to those performing this ritual in this locale. This supports and builds on the work of Hall (2006) and the notion of containment and resistance. That is those resisting are still affiliated in some way to a dominant social culture even where the practice differs. Although there would appear to be resistance, this still occurs within pre-existing or managed boundaries.

Thirdly this paper further supports the work of Kjeldgaard and Askegaard (2006) who indicate that youth have diverse localised meanings for consumption practices. In the context of the appropriation of this ritual event it has been noted that differing degrees of appropriation have been adopted and that the meaning or interpretation of the event has been conducted both individually and as a group. The suggested homogeneity of the youth market has been again questioned in this paper and although perceptions of the event were rooted in 
popular culture, the meaning of the prom was indicative of the UK consumers own recognisable experiences (Hall, 2006) be that the socio-cultural context, the local content or their friendship group influence. Interestingly not one account of the prom was the same and although some similar experiences were identified in the narratives the variety associated with the (re) creation of the prom illustrated innovation and creativity in approach. Further studies ought to reflect this diversity and seek to understand the influences affecting degrees of appropriation. The role of the school as a socialising agent specifically in this context needs exploration.

\section{Managerial Implications}

The school prom is a growth market. Not only has it been adopted in the UK at secondary school level (to recognise the transition from school to employment or further education) but it has been sporadically performed at primary/junior school as well to mark the change for those going to high school. Clearly the socialising agents (e.g. schools and parents) will be more involved with younger children and their appropriation of this ritual event and the 'junior prom' could be useful in providing a platform for social recognition furthering the notion of parental social capital as posited by Putnam (2000). Williams (2009) recently coined the expression 'Manger Chic'; an observation that competitive parents were prepared to spend considerable sums to ensure their children taking part in the Nativity play were able to 'excel' at a very early age. This translated into materialistic consumption behaviour. If bridesmaid dresses for angels and pashmina shawls for the angel Gabriel in reception classes are an indication of potential spend, the market for the artefacts (Rook, 1985) for a 'mini-me' junior prom could be exponential.

Whilst this paper focuses on the UK (and more specifically Scotland) the High School Prom phenomenon could become more widespread if as Disney propose High School Musical is 
made with Chinese actors for an Asian audience. Whilst the appropriation of the High School Prom would be performed in a different cultural context, the potential for (re) creation and the associated marketing and consumption of the artefacts (e.g. dresses, shoes, jewellery, limos etc.), for example, could have significant implications for existing or new businesses interested in developing and growing this market. In particular, this paper has illustrated that there are particular icons that have priority for adolescents engaging with the prom in the UK (e.g. the dress) and Grayson and Martinec's (2004) study could be further developed by exploring the significance of icons in culturally based situations.

What perhaps was most evident in the interviews was the desire of the respondents, regardless of their role (e.g. 'insider' or 'tourist'), to have 'ownership' of the prom. Consistently the adolescents were motivated by personalising the prom, making it 'distinctive' from proms that previous school pupils had organised and ensuring some element of the local. There was also support in the data to suggest that those attending the prom post rationalised the experience - sometimes negatively - but this often occurred when the prom had been disappointing because of the lack of script or structure to the event or because of a poor service experience. Although this needs further research, it is interesting to note that it would appear that by personalising aspects of the prom venues hosting the event, for example, have the opportunity to encourage re-booking and positive word of mouth. Suggestions for this include providing web-pages that would allow the youth market to create their own 'momentous' prom (akin to the Mini web site which affords consumers the opportunity to create their own car) and, to overcome post-purchase dissonance, some direct mail material (using photographs taken during the evening) to reinforce the special and distinctive nature of that particular prom. Additionally the youth market should be treated in the same way businesses behave with other clients. Some of the discourse with the organising 
committee members suggests that whilst businesses are 'happy to take our money' they often 'don't take us seriously'. These adolescents are not only familiar with the service industry; many of them also work in venues that hold such events. They are aware of what they can reasonably expect and know what is acceptable. The youth market may be the future market but they have arrived. To be successful businesses have no option not only to acknowledge this change but rise to the challenge of both understanding and dealing with this diverse market. 


\section{References}

Arnett, J. (1995) Adolescents' uses of media for self-socalization, Journal of Youth and Adolescence 24 (5), pp.519-32 DOI: 10.1007/BF01537054

Arnould, E.J. \& Thompson, C.J. (2005) Consumer Culture Theory (CCT): Twenty Years of Research, Journal of Consumer Research, 31, pp.868-881 DOI: 10.1086/426626

Arnould, E.J. \& Price, L.L. (2000), Authenticating Acts and Authoritative Performances:

Questing for Self and community. In C.Huffman, S. Ratneswar \& D.G.Mick (Eds.), The Why of Consumption: Contemporary Perspectives on Consumer Motives (pp.140-163). New York: Routledge

Arthur, D. (2006) Authenticity and consumption in the Australian Hip Hop culture, Qualitative Market Research: An International Journal, 9 (2), pp. 140-156 DOI: 10.1108/13522750610658784

Baudrillard, J. (1983) Simulations. New York: Semiotext(e), Inc.

Best, A. L. (2000) Prom Night: Youth, Schools and Popular Culture. New York:

Routledge/Farmer

Beverland, M.B., Lindgreen, A. \& Vink, M.W. (2008) Projecting Authenticity Through Advertising: Consumer Judgments of Advertisers' Claims, Journal of Advertising, 37 (1), pp.5-15 DOI: 10.2753/JOA0091-3367370101

Brown, S. \& Patterson, A. (2000) Knick-knack Paddy-whack, Give a Pub a Theme, Journal of Marketing Management, 16 (6), pp.647-662 DOI: 10.1362/026725700785045903

Bourdieu, P. (1984) Distinction: A Social Critique of the Judgement of Taste. London: Routledge and Kegan Paul (original work published 1979).

Bryman, A. \& Burgess, R.G. (1994) Analyzing Qualitative Data. London: Routledge Buckingham, D. (2009) The Impact of the Commercial World on Children's Wellbeing: Report of an Independent Assessment. Department for Children, Schools and Families and Department for Culture Media and Sport. Retrieved from DCSF website:

http://search.publications.dcsf.gov.uk/kbroker/dcsf/dcsfpubs/search.ladv?sr=0\&cs=UTF-

$8 \& \mathrm{sc}=$ dcsfpubs \&sf $=\& \mathrm{nh}=10 \& \mathrm{sb}=0 \& \mathrm{ha}=144 \& \mathrm{hs}=0 \& \mathrm{fl} 1=$ publicationshop\%3A\&op1=1\&ty1

$=0 \& \mathrm{tx} 1=2986 \& \mathrm{fl} 0=\& o p 0=1 \&$ ty $0=0 \& \mathrm{tx} 0=$ buckingham

Clay, A. (2003) Keepin' it Real Black Youth, Hip-Hop Culture, and Black Identity, American

Behavioral Scientist, 46 (10), pp.1346-1358 DOI: 10.1177/0002764203046010005

Cohen, E. (1979) Re-thinking the Sociology of Tourism, Research 6 (1), pp.18-35 DOI: 10.1016/0160-7383(79)90092-6

Duffy, M. (2007, September 8) Fizz, frocks and limos: get ready for the ultimate party, The Herald, pp.15

Ennett, S.T. \& Bauman, K.E. (1996) Adolescent Social Networks: School, Demographic, and Longitudinal Considerations, Journal of Adolescent Research, 11 (2), pp.194-215 DOI 10.1177/0743554896112003

Ferle, C. La., Edwards, S.M. \& Lee, W.N. (2000) Teens' use of traditional media the Internet, Journal of Advertising Research, 40, 3 pp.55-65. Retrieved from: http://www.jar.warc.com/ Firat, A. F. \& Venkatesh, A. (1995) Liberatory Postmodernism and the Re-enchantment of Consumption, Journal of Consumer Research, 22 (3), pp.239-67 Retrieved from:

http://www.journals.uchicago.edu/toc/jcr/current?cookieSet=1

Glaser, B \& Strauss, A. (1967) The Discovery of Grounded Theory: Strategies for Qualitative Research, Chicago: Aldine

Gottdiener, M. (1997) The Theming of America, Boulder, CO: Westview

Grayson, K. \& Shulman, D. (2000), Indexicality and the Verification Function of Irreplaceable Possessions: A Semiotic Analysis, Journal of Consumer Research, 27 (1), pp.17-30 Retrieved from: http://www.journals.uchicago.edu/toc/jcr/current?cookieSet=1 
Grayson, K. \& Martinec, R. (2004) Consumer Perceptions of Iconicity and Indexicality and Their Influence on Assessments of Authentic Market Offerings, Journal of Consumer

Research, 31, pp.296-312 Retrieved from:

http://www.journals.uchicago.edu/toc/jcr/current?cookieSet=1

Gronow, J. (2004) Standards of Taste and Varieties of Goodness: The (Un)predictability of Modern Consumption. In M. Harvey, A. McMeekin \& A.Warde (Eds.), Theoretical Approaches to Food Quality (pp.38-60). Manchester: Manchester University Press.

Guest G., Bruce, A. \& Johnson, L. (2006) How many interviews are enough? An experiment with data saturation and variability, Field Methods, 18, pp.59-82. DOI:

$10.1177 / 1525822 X 05279903$

Hall, S. \& Whannel, P. (2006) The Young Audience. In Storey, J. (Ed), Cultural Theory and Popular Culture, (pp.45-51) $3^{\text {rd }}$ Edition

Hall, S. (2006) Notes on Deconstructing the Popular. In Storey, J. (Ed) Cultural Theory and Popular Culture, (pp. 477-487) $3^{\text {rd }}$ Edition

Hektner, J.M. (1995) When Moving Up Implies Moving Out: Rural Adolescent Conflict in the Transition to Adulthood, Journal of Research in Rural Education, 11 (3), pp.3-14 Retrieved from: http://www.jrre.psu.edu/

Holland, J., Reynolds, T. \& Weller, S. (2007) Transitions, Networks and Communities: The Significance of Social Capital in the Lives of Children and Young People, Journal of Youth Studies, 10 (1) pp.97-116 DOI: 10.1080/13676260600881474

Hollensen, S. (2007) Global Marketing: A Decision-Oriented Approach, Harlow: Prentice Hall $4^{\text {th }}$ Edition

Hussey, J. \& Hussey, R. (1997) Business Research. A practical guide for undergraduate and postgraduate students. Hampshire, England: Macmillan Press.

Kandel, D.B. (1996) The Parental and Peer Context of Adolescent Deviance: An Algebra of

Interpersonal Influences, Journal of Drug Issues, 26, pp.298-315 Retrieved from:

http://www2.criminology.fsu.edu/ jdi/

Kjeldgaard, D. \& Askegaard, S. (2006) The Glocalization of Youth Culture: The Global Youth Segment as Structures of Common Difference, Journal of Consumer Research, 33, pp.231-247 Retrieved from: http://www.journals.uchicago.edu/toc/jcr/current?cookieSet=1

Kozinets, R., Sherry, J.F., Storm, D., Nuttavuthist, K. \& Deberry-Spence, B. (2004) Ludic Agency and Retail Spectacle, Journal of Consumer Research, 31, pp.658-672 Retrieved from: http://www.journals.uchicago.edu/toc/jcr/current?cookieSet=1

Lego, C. Wood, N., McFee, S. \& Solomon, M. (2002) A thirst for the real thing in themed environments: consuming authenticity in Irish pubs, Journal of Foodservice Business Research, 5 (2) pp.61-74 Retrieved from: http://www.tandf.co.uk/journals/WFBR

Munoz, C.L., Wood, N.T. \& Solomon, M.R. (2006) Real or blarney? A cross-cultural investigation of the perceived authenticity of Irish pubs, Journal of Consumer Behaviour, 5, pp. 222-234 DOI: 10.1002/cb.174

Nancarrow C., Tinson J. \& Brace I. (2008) Consumer Savvy and Intergenerational Effects, International Journal of Market Research, 50 (6), pp.731-755 Retrieved from: http://www.ijmr.com/

Nuttall, P. (2010a) Insiders, Regulars and Tourists: Exploring Selves and Music Consumption in Adolescence, forthcoming Journal of Consumer Behaviour

O’Guinn, T.C. \& Shrum, L.J. (1997) The role of television in the construction of consumer reality, Journal of Consumer Research, 23 (4), pp.278-84. Retrieved from:

http://www.journals.uchicago.edu/toc/jcr/current?cookieSet=1

Ostergaard, P., Fitchett, J.A. \& Jantzen, C. (1999) On Appropriation and Singuralisation:

Two Consumption Processes, Advances in Consumer Research, 26, pp.405-409 Retrieved from: http://www.acrwebsite.org/volumes/ 
Pyke, N. \& Bloomfield, S. (2004, July 11) The High School Prom arrives in UK (via stretch limo, naturally), The Independent Retrieved from:

http://www.independent.co.uk/news/education/education-news/the-high-school-prom-arrivesin-uk-via-stretch-limo-naturally-552740.html

Putnam, R. (2000) Bowling Alone: The Collapse and Revival of American Community, New York: Simon and Schuster

Ritzer, G. (1999) Enchanting a Disenchanted World: Revolutionizing the Means of Consumption, Thousand Oaks, CA: Pine Oaks/Sage

Rook, D.W. (1985) The Ritual Dimension of Consumer Behavior, Journal of Consumer

Research, 12, pp.251-264 Retrieved from:

http://www.journals.uchicago.edu/toc/jcr/current?cookieSet $=1$

Rose, R.L., Wood, S.L. (2005) Paradox and the Consumption of Authenticity Through Reality Television, Journal of Consumer Research, 32 (1), pp.284-96. DOI: 10.1086/432238

Shugart, H. (1997) Counterhegemonic acts: Appropriation as a feminist rhetorical strategy, Quarterly Journal of Speech, 83, pp.210-229 Retrieved from:

http://www.tandf.co.uk/journals/rqjs

Singh, A. (2008, October 7) High School Musical 3 Breaks Records, Telegraph Retrieved from: http://www.telegraph.co.uk/news/newstopics/celebritynews/3152740/High-SchoolMusical-3-breaks-records.html

Spiggle, S. (1994) Analysis and Interpretation of Qualitative Data in Consumer Research, Journal of Consumer Research, 21, pp.491-503 Retrieved from:

http://www.journals.uchicago.edu/toc/jcr/current?cookieSet=1

Sukalakamala, P. \& Boyce, J.B. (2007) Customer perceptions for expectations and acceptance of an authentic dining experience in Thai restaurants, Journal of Foodservice, 18 (2), pp.69-75 DOI 10.1111/j.1745-4506.2007.00048.x

Thompson, C.J. \& Hirschman, E. (1995) Understanding the Socialized Body: A

Poststructuralist Analysis of Consumers' Self-Conceptions, Body Images and Self-Care

Practices, Journal of Consumer Research, 22, pp.319-153 Retrieved from:

http://www.journals.uchicago.edu/toc/jcr/current?cookieSet $=1$

Tinson J. \& Nuttall P. (2010) Exploring Appropriation of Global Cultural Rituals forthcoming Journal of Marketing Management (Special Issue "Emerging Issues in Customer Behaviour in Multicultural Contexts")

Unruh,D. (1979) Characteristics and Types of Participation in Social Worlds, Symbolic Interaction 2, pp.115-29. DOI 10.1525/si.1979.2.2.115

Warde, A. (2005) Consumption and Theories of Practice, Journal of Consumer Culture, 5 (2), pp.131-153 DOI: 10.1177/1469540505053090

Williams, R. (2009, December 4) Manger Chic: Round yon virgin, a pashmina shawl, Guardian, pp.19 